\title{
Mechanisms of Sodium Transport at the Blood-Brain Barrier Studied with In Situ Perfusion of Rat Brain
}

\author{
*Steven R. Ennis, *Xiao-dan Ren, and *†A. Lorris Betz \\ Departments of * Surgery (Neurosurgery) and $\dagger$ Pediatrics and Neurology, \\ University of Michigan, Ann Arbor, Michigan, U.S.A.
}

\begin{abstract}
The mechanism of unidirectional transport of sodium from blood to brain in pentobarbital-anesthetized rats was examined using in situ perfusion. Sodium transport followed Michaelis-Menten saturation kinetics with a $V_{\max }$ of $50.1 \mathrm{nmol} / \mathrm{g} / \mathrm{min}$ and $\mathrm{a} K_{\mathrm{m}}$ of $17.7 \mathrm{mM}$ in the left frontal cortex. The kinetic analysis indicated that, at a physiologic sodium concentration, $\sim 26 \%$ of sodium transport at the blood-brain barrier (BBB) was carrier mediated. Dimethylamiloride $(25 \mu M)$, an inhibitor of $\mathrm{Na}^{+} / \mathrm{H}^{+}$exchange, reduced sodium transport by $28 \%$, whereas phenamil $(25 \mu M)$, a sodium channel inhibitor, reduced the transfer constant for sodium by $22 \%$. Bumetanide $(250 \mu M)$ and hydrochlorothiazide $(1.5 \mathrm{mM})$, inhibitors of $\mathrm{Na}^{+}-\mathrm{K}^{+}-2 \mathrm{Cl} / \mathrm{NaCl}$ symport, were ineffective in reducing blood to brain sodium transport. Acetazolamide $(0.25 \mathrm{mM})$, an inhibitor of carbonic anhydrase, did not change sodium transport at the BBB. Finally, a perfusate $\mathrm{pH}$ of 7.0 or 7.8 or a perfusate $\mathrm{PCO}_{2}$ of $86 \mathrm{~mm} \mathrm{Hg}$ failed to change sodium transport. These results indicate that $50 \%$ of transcellular transport of sodium from blood to brain occurs through $\mathrm{Na}^{+} / \mathrm{H}^{+}$exchange and a sodium channel in the luminal membrane of the BBB. We propose that the sodium transport systems at the luminal membrane of the $\mathrm{BBB}$, in conjunction with $\mathrm{Cl}^{-} / \mathrm{HCO}_{3}{ }^{-}$exchange, lead to net $\mathrm{NaCl}$ secretion and obligate water transport into the brain. Key Words: Brain-Blood-brain barrier-Transport-Sodium - In situ perfusion. J. Neurochem. 66, 756-763 (1996).
\end{abstract}

The blood-brain barrier (BBB) serves not only to restrict the movement of water-soluble solutes between blood and brain but also to regulate the ionic composition of the interstitial fluid through transport of $\mathrm{Na}^{+}$ and $\mathrm{K}^{+}$(Schiclke and Betz, 1993). Previous reports have provided evidence for both $\mathrm{NaCl}$ cotransport and a nonselective sodium channel in the luminal membrane of the BBB (Betz, 1983a) and for an $\mathrm{Na}^{+}, \mathrm{K}^{+}-$ ATPase and $\mathrm{Na}^{+} / \mathrm{H}^{+}$exchange in the abluminal membrane (Betz, 1983b). Vigne et al. (1989), using the patch clamp technique, confirmed that cultured brain endothelial cells contain a nonselective cation channel, but they did not specify the location of the channel to either the luminal or abluminal membrane. On the basis of in vivo studies, Murphy and Johanson (1989) reported that metabolic acidosis and amiloride but not acetazolamide inhibit sodium transport at the BBB, and they postulated an $\mathrm{Na}^{+} / \mathrm{H}^{+}$exchange mechanism in the luminal membrane. Thus, taken together, the available data suggest the unlikely possibility that the luminal membrane of the BBB contains three different types of sodium transport mechanisms.

The present studies were designed to define better the mechanisms of sodium transport at the luminal membrane of the BBB using in situ perfusion of the rat brain. The main advantage of in situ perfusion is that it allows us to control precisely the concentration of inhibitors used to study sodium transport. Finally, because amiloride has affinity for several of the carriermediated sodium transport systems and the sodium channel, we have used the more specific amiloride analogues to characterize sodium transport (Kleyman and Cragoe, 1988).

Our basic hypothesis was that blood to brain sodium movement is both carrier and channel mediated. The specific questions we sought to answer were the following: (a) Is blood to brain sodium transport subject to saturation kinetics? (b) Is blood to brain sodium transport inhibited by the $\mathrm{Na}^{+} / \mathrm{H}^{+}$exchange inhibitor dimethylamiloride (DMA), the sodium channel inhibitor phenamil (PAM) (Kleyman and Cragoe, 1988), the $\mathrm{Na}^{+} / \mathrm{Cl}^{-}$cotransport inhibitors bumetanide and hydrochlorothiazide (HCTZ) (Cremaschi et al., 1992), or inhibitors of carbonic anhydrase, such as acetazolamide? (c) Is blood to brain sodium transport affected by short-term ( $\leq 10-\mathrm{min})$ changes in $\mathrm{pH}$ ?

Resubmitted manuscript received August 15, 1995; accepted September 18, 1995.

Address correspondence and reprint requests to Dr. S. R. Ennis at Department of Surgery ( Neurosurgery), R5605 Kresge I, University of Michigan, Ann Arbor, MI 48109-0532, U.S.A.

Abbreviations used: AIB, $\alpha$-aminoisobutyric acid; BBB, bloodbrain barrier; DMA, dimethylamiloride; HCTZ, hydrochlorothiazide; PAM, phenamil; $p C B F$, perfusate cerebral blood flow; $p C P V$, perfusate cerebral plasma volume; $P S$ product, permeability-surface area product; $\mathrm{RBC}$, red blood cell. 
Some of our results were presented in a preliminary communication (Ennis et al., 1993).

\section{MATERIALS AND METHODS}

Transport of sodium and $\alpha$-aminoisobutyric acid (AIB) across the BBB was measured using in situ perfusion of rat brain. as previously described (Ennis et al., 1994). In brief, male, Long-Evans rats, weighing $300-450 \mathrm{~g}$, were anesthelised with pentobarbital $(65 \mathrm{mg} / \mathrm{kg}$ ). The right and left common carotid and pterygopalatine arteries were isolated, and the pterygopalatine arteries were ligated. Catheters of PE50) lubing, filled with heparinized saline, were placed in the left femoral artery and in the left external carotid artery. Rats were heparinized ( 1.2 units/g of body weight), and samples for blood gases obtained from the left femoral artery. The kil external carotid artery cannula was used for retrograde prrfusion of sheep red blood cells (RBCs) in saline at a temperature of $37^{\circ} \mathrm{C}$. The perfusate was infused at a rate of $4 \mathrm{ml} / \mathrm{min}$. We have previously shown that this perfusion rate is itdequate for maintenance of the EEG (Ennis et al., 1994). $\Lambda$ hematocrit of $0.3-0.35$ was used for these studies. A mixture of $30 \%$ oxygen and $70 \%$ air was delivered by lace mask to improve oxygenation of animals during the preperfusion period. Femoral and carotid blood pressures were continuously recorded through transducers connected to the arlerial catheters. Blood pressure and EEG were recorded using a Biopac MP100 data acquisition system. The body lemperature was maintained between 37.5 and $38.5^{\circ} \mathrm{C}$ using it rectal Thermistor connected to a temperature monitor/controller.

\section{Measurement of blood to brain transport during in situ perfusion}

Blood to brain permeability-surface area products ( $P S$ products ) for $\left[{ }^{3} \mathrm{H} \mid \mathrm{AIB}(0.5 \mu \mathrm{Ci} / \mathrm{ml})\right.$, a marker for passive permeability, and ${ }^{2-} \mathrm{Na}^{+}(0.5 \mu \mathrm{Ci} / \mathrm{ml})$ were determined using a 10 -min perfusion. We have provided evidence that in the presence of $2 \mathrm{mM}$ phenylalanine the transport of AIB from blood to brain occurs only by passive transport during the 10 min used for current in situ perfusion experiments (Ennis $\left(4\right.$ all. 1994). The PS product for $\left[{ }^{3} \mathrm{H}\right]$ AIB was measured for all animals in this study. Supplemental pentobarbital ( 22 $m \mathrm{mg} / \mathrm{kg}$ ) was given just before perfusion to prevent the animals awakening during the perfusion. Following the perfusion, the brain was removed, and the hemispheres were bisected and dissected into frontal, parietal, and occipital cortices and diencephalon. Brain and perfusion fluid samples were dissolved in methylbenzthonium hydroxide and prepared for liquid scintillation counting.

\section{Composition of perfusion fluids}

Blood was stored at $4^{\circ} \mathrm{C}$ until the day of use. Whole blood wils centrifuged at $1,660 \mathrm{~g}$ for $10 \mathrm{~min}$ at $8^{\circ} \mathrm{C}$, and the plasma and white blood cells were discarded. The lightly packed $\mathrm{RBC}$ s were washed twice by centrifugation in 1.5 volumes of $0.9 \% \mathrm{NaCl}$ and twice by centrifugation in 1.5 volumes of perfusate saline. After the final spin, the RBCs were filtered through nylon mesh (pore size, $150 \mu \mathrm{m}$ ) and resuspended at a hematocrit of 0.3 in the perfusate. The composition of the control saline used to make the RBC-containing perfusate was $118 \mathrm{mM} \mathrm{NaCl}, 3 \mathrm{~m} M \mathrm{KCl}, 1.2 \mathrm{mM} \mathrm{MgSO}_{4}, 1.2 \mathrm{~m} M$ $\mathrm{KH}_{2} \mathrm{PO}_{4} .24 \mathrm{~m} M \mathrm{NaHCO}_{3}, 2.5 \mathrm{~m} M \mathrm{CaCl}_{2}, 10 \mathrm{~m} M$ glucose, and $2 \mathrm{~m} M$ phenylalanine. The perfusate containing radioaclive isotopes was gently bubbled with a mixture of oxygen and carbon dioxide to maintain the $\mathrm{pH}$ in the range 7.357.45. Inhibitors of ion transport were dissolved in saline and included in the final perfusate at the concentrations given in the text.

The perfusates with a reduced sodium concentration were mixtures of Tris-HCl, Tris-base, and $24 \mathrm{~m} M$ Tris-carbonate as substitutes for $\mathrm{NaCl}$ and $\mathrm{NaHCO}_{3}$. Sodium and potassium concentrations were confirmed using a flame photometer (IL 943), and chloride levels were measured using a chloridometer (Haake-Buchler Instruments).

Normocapnic perfusates with either a low or high $\mathrm{pH}$ were created by changing the amount of $\mathrm{NaHCO}_{3}$, along with appropriate changes in the amount of $\mathrm{NaCl}$ included in the perfusate, to maintain a constant osmolality. The low $\mathrm{pH}$ perfusate contained $130 \mathrm{~m} M \mathrm{NaCl}, 3 \mathrm{~m} M \mathrm{KCl}, 1.2 \mathrm{~m} M$ $\mathrm{MgSO}_{4}, 1.2 \mathrm{~m} M \mathrm{KH}_{2} \mathrm{PO}_{4}, 9.98 \mathrm{~m} M \mathrm{NaHCO}_{3}, 2.5 \mathrm{~m} M$ $\mathrm{CaCl}_{2}, 10 \mathrm{~m} M$ glucose, and $2 \mathrm{~m} M$ phenylalanine with a $\mathrm{pH}$ of $7.01 \pm 0.01$. The high $\mathrm{pH}$ perfusate contained $77 \mathrm{mM}$ $\mathrm{NaCl}, 3 \mathrm{~m} M \mathrm{KCl}, 1.2 \mathrm{~m} M \mathrm{MgSO}_{4}, 1.2 \mathrm{~m} M \mathrm{KH}_{2} \mathrm{PO}_{4}, 62.9$ $\mathrm{m} M \mathrm{NaHCO}_{3}, 2.5 \mathrm{~m} M \mathrm{CaCl}_{2}, 10 \mathrm{~m} M$ glucose, and $2 \mathrm{~m} M$ phenylalanine with a $\mathrm{pH}$ of $7.76 \pm 0.01$. The hypercapnic perfusate, with a normal $\mathrm{pH}$, contained $91.9 \mathrm{mM} \mathrm{NaCl}, 3$ $\mathrm{m} M \mathrm{KCl}, 1.2 \mathrm{~m} M \mathrm{MgSO}_{4}, 1.2 \mathrm{~m} M \mathrm{KH}_{2} \mathrm{PO}_{4}, 50.1 \mathrm{~m} M$ $\mathrm{NaHCO}_{3}, 2.5 \mathrm{mMCaCl}, 10 \mathrm{~m} M$ glucose, and $2 \mathrm{mM}$ phenylalanine with a $\mathrm{pH}$ of $7.35 \pm 0.01$ and $\mathrm{PCO}_{2}$ of $85.6 \pm 1.61$ $\mathrm{mm} \mathrm{Hg}$.

\section{Calculation of rate constants for $\mathrm{BBB}$ permeability to $\mathrm{AIB}$ and $\mathrm{Na}^{+}$}

The rate constant for movement of solute across the BBB was calculated from the following equation:

$$
K_{\mathrm{i}}=A_{\mathrm{b}} /\left(C_{\mathrm{p}} \times T\right)
$$

where $A_{\mathrm{b}}$ is the amount of solute in the brain per unit mass of tissue $(\mathrm{dpm} / \mathrm{g}), C_{\mathrm{p}}$ is the perfusate solute concentration (dpm/ml), and $T$ is time. In the present experiments $C_{\mathrm{p}}$ is constant.

The $K_{\mathrm{i}}$ values measured in this study were $<1 \%$ of the rate of blood flow that we reported previously for in situ perfusion of the rat brain (Ennis et al., 1994). Consequently, $K_{\mathrm{i}}$ closely approximates the $P S$ product as described by Fenstermacher et al. (1981). The PS product for a substance at the $\mathrm{BBB}$ is the product of the permeability $(P)(\mathrm{cm} / \mathrm{min})$ and the surface area $(S)\left(\mathrm{cm}^{2} / \mathrm{g}\right)$.

Uptake data were corrected for the amount of tracer that remains within the vascular space of the brain by the following equation:

$$
A_{\mathrm{b}}=A_{\mathrm{t}}-\left(p C P V \times C_{\mathrm{p}}\right)
$$

where the $p C P V$ is the perfusate cercbral plasma volume. An average $p C P V$ in the present study was determined in separate groups of animals, from the amount of $\left[{ }^{3} \mathrm{H}\right]$ inulin in the brain samples (assuming no tissue uptake).

The transfer constant for sodium was also determined from a multiple time/graphical analysis. The following equation describes the relationship between the amount of tracer in the brain $\left(A_{\mathrm{b}}\right)$ and its concentration in plasma:

$$
A_{\mathrm{b}}=K_{\mathrm{i}} \times \int C_{\mathrm{p}} d t+V_{\mathrm{b}} \times C_{\mathrm{p}}(T)
$$

where $V_{\mathrm{b}}$ is the sum of the plasma and rapidly filling spaces $\left(V_{\mathrm{b}}=p C P V+V_{\mathrm{r}}\right) . V_{\mathrm{r}}$ is termed the rapidly filling space because it rapidly and reversibly exchanges with plasma (Patlak et al., 1983). Under initial velocity conditions, a plot 
of $A_{\mathrm{b}} / C_{\mathrm{p}}(T)$ versus perfusion time is a straight line with the slope $=K_{\mathrm{i}}$ and the $y$-intercept $=V_{\mathrm{b}}$.

The time of isotope circulation ranged between 6 and 18 min. The transfer constant for sodium was measured in two groups of animals: (a) animals perfused with sheep RBCs in a saline containing a physiological sodium concentration $(\mathrm{n}=11)$ and (b) animals perfused with sheep RBCs in a saline containing a low sodium concentration $(0.2 \mathrm{mM})(\mathrm{n}$ $=10)$.

\section{Kinetics of transport from perfusate to brain}

Carrier-mediated, unidirectional influx at the BBB is commonly described by the Michaelis-Menten equation (Pardridge, 1983). Because $v=P S \times C$, where $v$ is the velocity of transport and $C$ is concentration, then

$$
P S=\left(V_{\text {max }}\right) /\left(K_{\mathrm{m}}+C_{\mathrm{p}}\right)+K_{\mathrm{D}}
$$

where $V_{\max }$ is the maximal velocity of transport, $K_{\mathrm{m}}$ is the affinity constant, and $K_{\mathrm{D}}$ is the diffusion constant. When $K_{\mathrm{i}}$ $\cong P S$, the capillary concentration does not change appreciably as a result of uptake into the brain, and $C_{\mathrm{p}}$ approximates the mean capillary concentration.

Carrier-mediated sodium uptake across the BBB was investigated in a group of 22 animals in which perfusate sodium concentration was varied between 0.5 and $137 \mathrm{mM}$. The PS products for both $\left[{ }^{3} \mathrm{H}\right] \mathrm{AIB}$ and ${ }^{22} \mathrm{Na}$ were measured in these animals. The data were fitted to Eq. 4 using nonlinear regression analysis.

\section{Perfusate cerebral blood flow ( $p C B F$ )}

The $p C B F$ was calculated using ${ }^{14} \mathrm{C}$-labeled iodoantipyrine as the blood flow indicator. The uptake of iodoantipyrine is flow-limited at a $p C B F$ of $<1.8 \mathrm{ml} / \mathrm{g} / \mathrm{min}$ (Sakurada et al., 1978). Under these conditions, the $p C B F$ was calculated as follows:

$$
p C B F=-3.2 \ln \left[1-A_{\mathrm{b}} /\left(0.8 \times C_{\mathrm{p}}\right)\right]
$$

Animals were preperfused for $10 \mathrm{~min}$ with the appropriate solution before the $p C B F$ was determined. Radiolabeled iodoantipyrine was perfused into the external carotid artery for $15 \mathrm{~s}$ to measure $p C B F$.

\section{Statistical analysis}

Data for single time point $P S$ products (Eq. 1) were analyzed using a model 1 ANOVA with either an unpaired, two tailed $t$ test or with a two-tailed Dunnett's post hoc test for multiple comparisons. The Systat statistical software was used for these comparisons. Transfer constants using a graphical analysis were calculated by least squares regression analysis of the data fit to Eq. 3. The results were subjected to an analysis of covariance with a two-tailed $t$ test. The transport constants for Eq. 4 were calculated by a nonlinear, least squares regression analysis, using the BMDP-3R program. A $p$ value of $<0.05$ was considered significant.

\section{Chemicals and radiotracers}

$\left[{ }^{3} \mathrm{H}\right] \mathrm{AIB},\left[{ }^{3} \mathrm{H}\right]$ inulin, ${ }^{14} \mathrm{C}$-labeled iodoantipyrine, and ${ }^{22} \mathrm{Na}$ were purchased from Du Pont-NEN (Boston, MA, U.S.A.). DMA was purchased from Research Biochemicals International (Natick, MA, U.S.A.). All other chemicals were obtained from Sigma Chemical Co. (St. Louis, MO, U.S.A.) .

\begin{tabular}{|c|c|c|}
\hline & Mean $\pm S D$ & $n$ \\
\hline \multicolumn{3}{|l|}{ Animal parameter } \\
\hline Weight (g) & $368 \pm 47$ & 180 \\
\hline Femoral blood pressure $(\mathrm{mm} \mathrm{Hg})$ & $116 \pm 14$ & 180 \\
\hline Arterial $\mathrm{pH}$ & $7.34 \pm 0.05$ & 180 \\
\hline Arterial $\mathrm{PCO}_{2}(\mathrm{~mm} \mathrm{Hg})$ & $51 \pm 6$ & 180 \\
\hline Arterial $\mathrm{PO}_{2}(\mathrm{~mm} \mathrm{Hg})$ & $138 \pm 49$ & 180 \\
\hline Arterial hematocrit (\%) & $42 \pm 3$ & 180 \\
\hline Blood glucose (mg/dl) & $118 \pm 19$ & 159 \\
\hline Plasma sodium $(\mathrm{mEq} / \mathrm{L})$ & $144 \pm 5$ & 180 \\
\hline Plasma potassium (mEq/L) & $4.0 \pm 0.6$ & 180 \\
\hline Plasma chloride (mEq/L) & $106 \pm 6$ & 165 \\
\hline Plasma osmolality (mOsm) & $292 \pm 10$ & 180 \\
\hline \multicolumn{3}{|l|}{ Perfusate parameter } \\
\hline Perfusion pressure $(\mathrm{mm} \mathrm{Hg})$ & $96 \pm 30$ & 180 \\
\hline $\mathrm{pH}$ & $7.38 \pm 0.1$ & 152 \\
\hline $\mathrm{PCO}_{2}(\mathrm{~mm} \mathrm{Hg})$ & $37 \pm 7$ & 164 \\
\hline $\mathrm{PO}_{2}(\mathrm{~mm} \mathrm{Hg})$ & $300 \pm 74$ & 177 \\
\hline Hematocrit (\%) & $32 \pm 3$ & 180 \\
\hline Blood glucose $(\mathrm{mg} / \mathrm{dl})$ & $231 \pm 40$ & 155 \\
\hline Sodium $(\mathrm{mEq} / \mathrm{L})$ & $138 \pm 3$ & 152 \\
\hline Potassium (mEq/L) & $4.2 \pm 0.6$ & 180 \\
\hline Chloride $(\mathrm{mEq} / \mathrm{L})$ & $114 \pm 15$ & 165 \\
\hline Osmolality (mOsm) & $283 \pm 8$ & 180) \\
\hline
\end{tabular}

TABLE 1. Physiological parameters

Perfusion pressure is the carotid pressure minus the pressure due to the carotid cannula.

\section{RESULTS}

Table 1 presents the average values for blood gases, physiological parameters, and plasma osmolality and sodium, potassium, and glucose concentrations. These data were measured just before the beginning of a perfusion. These parameters were measured for the perfusate and are also included in Table 1. Perfusions in which the sodium concentration was manipulated are not included in Table 1. The values for these all parameters were significantly different $(p \leq 0.001)$ between plasma and perfusate. Before starting these experiments we realized it would not be possible to match plasma and perfusate exactly and chose to set the values for the perfusate as presented in Table 1. The small differences between plasma and perfusate are probably not physiologically significant.

\section{Graphical analysis of sodium transport}

Patlak et al. (1983) have shown that the use of graphical analysis of multiple-time uptake data allows the evaluation of the unidirectionality of transport and the influx rate constant, without the need for a correction for the vascular space. We used this method in our initial determination of the rate constant for $\mathrm{Na}^{+}$ influx across the BBB. Figure 1 presents a graphical analysis for $\mathrm{Na}^{+}$uptake in the frontal cortex using in situ perfusion with a perfusate containing either a normal $(138 \mathrm{~m} M)$ or a low $(0.2 \mathrm{mM})$ sodium concentration. Inspection of the regression lines for linearity for both high and low sodium perfusates indicates that during the $18 \mathrm{~min}$ of the perfusion, sodium transport 
FIG. 1. Graphical analysis of BBB permeability to sodium during perfusion with a perfusate with either a sodium concentration of $138 \mathrm{mM}(\mathrm{O}$; normal $\mathrm{Na} ; \mathrm{n}=11)$ or $0.2 \mathrm{mM}(\bullet$; low Na; $n=12$ ). Data were best fit by linear regression analysis to Eq. 3, where slope $=K_{\mathrm{i}}$ and intercept $=V_{\mathrm{r}} . K_{\mathrm{i}}=1.1 \pm 0.2$ $\mathrm{\mu l} / \mathrm{g} / \mathrm{min}, V_{\mathrm{r}}=7.7 \pm 2.2 \mu \mathrm{l} / \mathrm{g}, r$

$0.83, p \equiv 0.002$ for normal

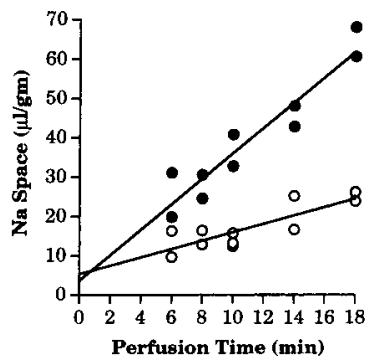
sodium; $K_{\mathrm{i}}=3.2 \pm 0.3 \mu \mathrm{l} / \mathrm{g} / \mathrm{min}, V_{\mathrm{r}}=5.0 \pm 3.3 \mu \mathrm{l} / \mathrm{g}, r=0.95$ $\rho \sim 0.001$ for low sodium. Data are mean \pm SE (bars) values.

remained unidirectional. The transfer constant for $\mathrm{Na}^{+}$ during perfusion with a normal sodium concentration was $1.1 \pm 0.2 \mu \mathrm{l} / \mathrm{g} / \mathrm{min}$ with a rapidly filling space of $5.3 \pm 2.8 \mu \mathrm{l} / \mathrm{g}$. Data are mean $\pm \mathrm{SE}$ values. The transfer constant during in situ perfusion with a low sodium perfusate was significantly increased ( $p$ $\because 0.00 \mathrm{l}$ by $t$ test ) to $3.2 \pm 0.4 \mu \mathrm{l} / \mathrm{g} / \mathrm{min}$, as anticipated lor carrier-mediated transport at the BBB. Carrier-mediated transport is subject to self-inhibition, and therefore a low sodium concentration should result in a significant increase in the transfer constant for sodium. These results confirm carrier-mediated transport for sodium at the BBB. In addition, the demonstration of unidirectional sodium transport during a 20 -min perfusion validates the use of 10 -min, single time point studies for the remainder of this study.

Kinetics of sodium transport in the frontal cortex

Figure $2 \mathrm{~A}$ presents the sodium $P S$ product as a function of the sodium concentration in the perfusate. These data were best fit by nonlinear least squares regression
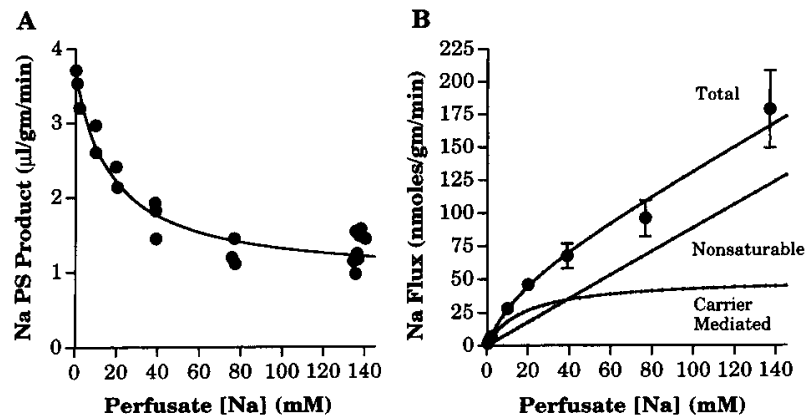

FIG. 2. Kinetic analysis of sodium transport from blood into the frontal cortex. A: Sodium PS product as a function of sodium concentration in the perfusate. Data were best fit by nonlinear regression analysis to Eq. 4 in a group of 22 animals, where $V_{\max }$

$50.1 \pm 11.8 \mathrm{nmol} / \mathrm{g} / \mathrm{min}, K_{\mathrm{m}}=17.7 \pm 4.1 \mathrm{mM}$, and $K_{\mathrm{D}}=0.88$

$0.11 \mu \mathrm{l} / \mathrm{g} / \mathrm{min}$. B: Data from $A$ were averaged at each sodium concentration and multiplied by the sodium concentration to give the total flux. Also shown is the fraction of the total sodium flux that proceeds either through carrier-mediated transport or by diffusion. Lines for the total, nonsaturable, and carrier-mediated flux are drawn by interpolation through the points predicted by Eq. 5 and the kinetic constant from A. Data are mean \pm SE (bars) values.

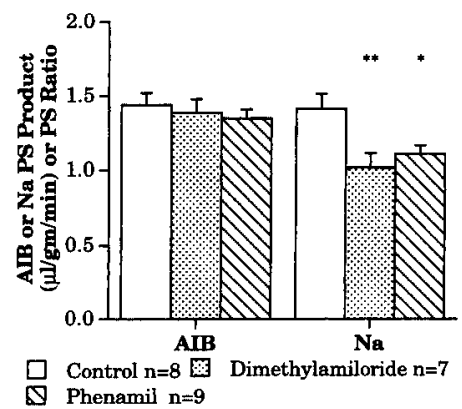

FIG. 3. Effect of inhibitors of sodium transport on the $A \mid B$ and $\mathrm{Na} P S$ products or the ratio of Na/AIB. The inhibitors, either 25 $\mu M$ DMA or $25 \mu M$ PAM, were included in the perfusate during a 10-min perfusion. Groups were compared using ANOVA with a Dunnett's test for multiple comparisons: ${ }^{*} p \leq 0.05,{ }^{*} p \leq 0.01$ versus control. Data are mean $\pm S E$ (bars) values.

analysis to Eq. 4. $V_{\text {mix }}$, the maximal velocity of transport, was $50.1 \pm 11.8 \mathrm{nmol} / \mathrm{g} / \mathrm{min}$, whereas the affinity constant, $K_{\mathrm{m}}$, was $17.7 \pm 4.1 \mathrm{~m} M$. Also shown is the diffusion constant for sodium at the BBB, which had a value of $0.88 \pm 0.11 \mu \mathrm{l} / \mathrm{g} / \mathrm{min}$. The $P S$ product for AIB (data not shown) did not change from control values in perfusates with a reduced sodium concentration.

Multiplying the $P S$ product for sodium by its concentration, $C$, in the perfusate gives the unidirectional flux. Figure 2B shows the total sodium flux into the brain as a function of perfusate sodium concentration. Also presented are the curves describing the carriermediated fraction and the nonsaturable portion of the total flux that moves by diffusion, either through ion channels or through membrane pores. At a sodium concentration of $140 \mathrm{~m} M$ the carrier-mediated fraction represents $\sim 28 \%$ of the total flux.

\section{Inhibition of blood to brain sodium transport}

The advent of the new generation of more specific amiloride analogues permits the identification of various $\mathrm{Na}^{+}$transport processes (Kleyman and Cragoe, 1988 ). Figure 3 presents data on the effect of the amiloride analogues DMA and PAM on the PS products for $\mathrm{AIB}$ and $\mathrm{Na}^{+}$products during a $10-$ min perfusion. DMA, an inhibitor of $\mathrm{Na}^{+} / \mathrm{H}^{+}$exchange, at a concentration of $25 \mu \mathrm{M}$ reduced the blood to brain sodium $P S$ product by $28 \%$ ( $p \leq 0.01$ by Dunnett's test ) without a significant change in AIB permeability. The sodium channel inhibitor PAM $(25 \mu M)$ also reduced unidirectional sodium influx by $22 \%(p \leq 0.05)$.

In contrast to the amiloride analogues, inhibitors of $\mathrm{Na}^{-} / \mathrm{K}^{+} / 2 \mathrm{Cl}^{-}$or $\mathrm{NaCl}$ symport were ineffective in reducing blood to brain sodium transport. Table 2 presents data for the effect of these inhibitors on sodium transport during in situ perfusion. The relatively high concentrations of $250 \mu M$ bumetanide or $1.5 \mathrm{mM}$ HCTZ were without effect on sodium or AIB uptake.

Figure 4 presents the effect of acetazolamide $(0.25$ $\mathrm{m} M$ ) included in the perfusate during a 10 -min experi- 
TABLE 2. Effect of modifiers of sodium transport

\begin{tabular}{llrr}
\hline & \multicolumn{2}{c}{$P S(\mu 1 / \mathrm{g} / \mathrm{min})$} & \\
\cline { 2 - 3 } \multicolumn{1}{c}{ Condition } & AlB & $\mathrm{Na}$ & $\mathrm{n}$ \\
\hline Control & $1.63 \pm 0.07$ & $1.22 \pm 0.05$ & 11 \\
Bumetanide $(250 \mu M)$ & $1.51 \pm 0.10$ & $1.20 \pm 0.08$ & 9 \\
HCTZ $(1.5 \mathrm{~m} M)$ & $1.69 \pm 0.18$ & $1.49 \pm 0.21$ & 6 \\
\hline
\end{tabular}

Data are mean $\pm S F$ values.

ment. Acetazolamide could lead to a decrease in the sodium $P S$ product through an inhibition of carbonic anhydrase present in the brain capillary endothelial cells (Ghandour et al., 1992). Inhibition of carbonic anhydrase could lead to an increase in the $\mathrm{pH}$ of the brain capillary endothelial cell. This change in cellular $\mathrm{pH}$ could decrease the $\mathrm{H}^{+}$gradient across the luminal membrane of the brain capillary endothelial cell (from cell to blood) and result in an inhibition of $\mathrm{Na}^{+} / \mathrm{H}^{+}$ exchange. Acetazolamide at this concentration had no effect on either the sodium $P S$ or AIB PS product. Also included in the legend for Fig. 4 are the $\mathrm{pH}$ and $\mathrm{PCO}_{2}$ for the control and acetazolamide-containing perfusates. There were no significant differences in these parameters.

The presence of DMA-sensitive $\mathrm{Na}^{+} / \mathrm{H}^{+}$exchange at the $\mathrm{BBB}$ led us to hypothesize that a decrease in blood $\mathrm{pH}$ would decrease the sodium PS product by decreasing the $\mathrm{H}^{+}$gradient across the luminal membrane of the brain capillary endothelial cell. Using similar reasoning we speculated that an increase in blood $\mathrm{pH}$ might stimulate $\mathrm{Na}^{+}$transport by increasing the $\mathrm{H}^{+}$gradient from the capillary endothelial cell to blood. Table 3 shows that perfusion of the brain with normocapnic blood at a $\mathrm{pH}$ of 7.0 or 7.76 did not result in a change in either the AIB or sodium $P S$ product.

Also presented in Table 3 is an experiment in which the $\mathrm{pH}$ was normal at a value of 7.4 but the $\mathrm{PCO}_{2}$ was increased to $86 \mathrm{~mm} \mathrm{Hg}$. An increase in blood $\mathrm{PCO}_{2}$ failed to increase significantly the sodium $P S$ product. We expected that an increase in the $\mathrm{H}^{+}$concentration within the capillary endothelial cells due to the action of carbonic anhydrase on the increased $\mathrm{CO}_{2}$ level would stimulate transport through the $\mathrm{Na}^{+} / \mathrm{H}^{+}$exchanger in the luminal membrane. We speculate that

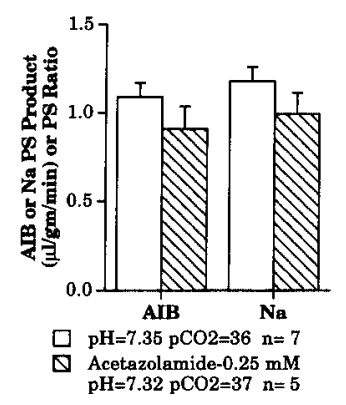

FIG. 4. Effect of acetazolamide on the AIB and Na PS products or the ratio of $\mathrm{Na} / \mathrm{AlB}$. Acetazolamide $(0.25 \mathrm{mM})$ was included in the perfusate during a $10-\mathrm{min}$ perfusion. Groups were compared using an unpaired $t$ test. Data are mean $\pm \mathrm{SE}$ (bars) values. the increase in the $\mathrm{PCO}_{2}$ of the perfusate during the 10min perfusion did not lead to a significant increase in the $\mathrm{H}^{+}$concentration of the brain endothelial cell.

There was a small, $<9 \mathrm{~mm} \mathrm{Hg}$, difference in the $\mathrm{PCO}_{2}$ of the control and low $\mathrm{pH}$ perfusates. This difference was not considered important because a $52 \mathrm{~mm}$ $\mathrm{Hg}$ increase in the $\mathrm{PCO}_{2}$ did not significantly change the sodium PS product.

\section{Cerebral plasma volume and blood flow}

The calculation of an accurate $P S$ product requires the determination of the plasma volume (Eq. 2). The $p C P V$ and the $p C B F$ for experimental conditions and substances that were thought to have potential for changing $p C P V$ and $p C B F$ are presented in Table 4. Only the normocapnic perfusate with a $\mathrm{pH}$ of 7.76 resulted in a significant change in the $p C P V$.

The $p C B F$ was significantly increased by a hypercapnic $\left(\mathrm{PCO}_{2}=84 \mathrm{~mm} \mathrm{Hg}\right)$ perfusate with a physiological $\mathrm{pH}(7.38)$ by $65 \%$ ( $p \leq 0.001)$. Current evidence supports the idea that an increase in blood $\mathrm{PCO}_{2}$ results in a decrease in the $\mathrm{pH}$ of the extracellular fluid of the brain, causing a vasodilatation and an increase in the cerebral blood flow (Siesjö and Ingvar, 1983). Similarly, a normocapnic perfusate with a $\mathrm{pH}$ of 7.03 also significantly increased $(p \leq 0.001)$ the $p C B F$, probably through an increase in the $\mathrm{H}^{+}$content of the interstitial fluid of the brain. Again, there was a small increase in the $\mathrm{PCO}_{2}$ of the low pH perfusate, which we did not consider physiologically relevant.

The $p C B F$ was also increased by acetazolamide ( 1 $\mathrm{m} M$ ), from $1.03 \pm 0.04 \mathrm{ml} / \mathrm{g} / \mathrm{min}$ for control animals to $1.34 \pm 0.04 \mathrm{ml} / \mathrm{g} / \mathrm{min}$ for treated animals. Acetazolamide is thought to lead to cerebral hypercapnia and extracellular acidosis (Bickler et al., 1988). The effect of $25 \mu M$ DMA in the perfusate is also included in Table 4. Because this concentration of DMA produced a $28 \%$ decrease in the sodium PS product, we thought that the $\mathrm{pH}$ of the brain capillary endothelial might also decrease and lead to an increase in the $p C B F$. DMA had no significant effect on the $p C B F$, which may indicate that a larger change in $\mathrm{pH}$ is required to increase cerebral blood flow. These results on $P C B F$ indicate that the perfused rat brain is able to respond in a physiological fashion to known stimuli and confirm the viability of the preparation.

\section{DISCUSSION}

We have shown previously that in situ perfusion using sheep RBCs maintains the EEG and the $p C P V$ and $p C B F$ within the normal range of in vivo values, indicating that the technique provides adequate perfusion of the rat brain (Ennis et al., 1994). All of the animals in the present study had an intact EEG during the time course of a perfusion.

\section{Sodium transport from blood to brain}

The mechanisms of blood to brain sodium transport are not well characterized. It has been proposed that 
TABLE 3. Effect of $\mathrm{pH}$ and $\mathrm{PCO}_{2}$ on $\mathrm{AIB}$ and sodium transport

\begin{tabular}{|c|c|c|c|c|c|}
\hline \multirow[b]{2}{*}{ Condition } & \multirow[b]{2}{*}{$\mathrm{pH}$} & \multirow[b]{2}{*}{$\mathrm{PCO}_{2}$} & \multicolumn{2}{|c|}{$P S(\mu 1 / \mathrm{g} / \mathrm{min})$} & \multirow[b]{2}{*}{$\mathrm{n}$} \\
\hline & & & AIB & $\mathrm{Na}$ & \\
\hline Low $\mathrm{pH} /$ normal $\mathrm{PCO}_{2}$ & $7.01 \pm 0.01^{a}$ & $41.8 \pm 2.1^{\prime \prime}$ & $1.05 \pm 0.16$ & $1.27 \pm 0.19$ & 6 \\
\hline Control & $7.36 \pm 0.01$ & $33.1 \pm 1.1$ & $1.23 \pm 0.10$ & $1.42 \pm 0.14$ & 12 \\
\hline High $\mathrm{pH} /$ normal $\mathrm{PCO}_{2}$ & $7.76 \pm 0.01^{\circ}$ & $36.1 \pm 1.0$ & $1.43 \pm 0.06$ & $1.27 \pm 0.06$ & 7 \\
\hline Normal $\mathrm{pH} /$ high $\mathrm{PCO}_{2}$ & $7.35 \pm 0.01$ & $85.6 \pm 1.6^{\prime \prime}$ & $1.50 \pm 0.16$ & $1.75 \pm 0.21$ & 10 \\
\hline
\end{tabular}

Data are mean \pm SE values.

${ }^{\prime} p \leq 0.001$ for comparison of control versus modified condition.

blood to brain sodium movement is by diffusion through neutral pores in the paracellular pathway, based on symmetrical diffusion potentials and the lack of selectivity to $\mathrm{Na}^{+}, \mathrm{K}^{+}$, and $\mathrm{Cl}^{-}$(Crone, 1984). The very low permeability of sodium at the BBB was resolved through postulating a small number of these pores (Crone, 1984). Damage to the microvessels during these experiments and the observation that $\mathrm{K}^{+}$exlibits a seven to 10 times higher permeability at the BBB than $\mathrm{Na}^{+}$were cited as evidence against the hypothesis that pores provide the major route for ion transport across the BBB (Schielke and Betz, 1993). Using in situ perfusion we have studied sodium transport at the luminal membrane of the BBB with a technique that is not hampered by the limitations of other methods (Takasato et al., 1984; Ennis et al., 1994). The main advantage of in situ perfusion is the ability 10 study unidirectional transport at a constant blood How, with a perfusate of known composition. As an example, the only previous determination of the kinetics of sodium transport from blood to brain used the intracarotid single injection technique (Betz, 1983a). The kinetics of sodium transport were determined relalive to those of L-glucose and showed a $K_{\mathrm{m}}$ of $2.5 \mathrm{~m} \mathrm{M}$. This value for the $K_{\mathrm{m}}$ is a factor of 8 less than the $17.7 \mathrm{~m} M$ from present study and probably reflects the mixing of a bolus injection with blood (Pardridge, 1)83).

It is interesting that at a sodium concentration of $140 \mathrm{~m} M$, the carrier-mediated portion of sodium flux represents $26 \%$ of the total flux, which is very similar 10 the $28 \%$ inhibition that results from including $25 \mu \mathrm{M}$
DMA in the perfusate. The similarity between these numbers suggests that $25 \mu M$ DMA completely inhibits the luminal $\mathrm{Na}^{+} / \mathrm{H}^{+}$exchanger. The $K_{\mathrm{m}}$, determined from the kinetics of sodium transport, of 17.7 $\mathrm{m} M$ is within the range of values of $15-18 \mathrm{~m} M$ characteristic of the different isoforms of $\mathrm{Na}^{+} / \mathrm{H}^{+}$exchangers (Levine et al., 1993).

Another $22 \%$ of the unidirectional sodium flux is mediated by a PAM-sensitive transport system. A PAM-sensitive, nonselective cation channel with a conductance of $23 \mathrm{pS}$ has been reported in cultured brain microvascular cells (Vigne et al., 1989). A nonselective cation channel with similar biophysical properties that is inhibited by atrial natriuretic peptide, intracellular cyclic GMP, and cyclic GMP kinase has also been reported in inner medullary collecting duct (Light et al., 1990). The luminal membrane of brain capillaries contains atrial natriuretic peptide receptors (Ermisch et al., 1991) coupled to guanylate cyclase (Steardo and Nathanson, 1987). Atrial natriuretic peptide inhibits amiloride-sensitive sodium transport in isolated brain capillaries (Ibaragi et al., 1989).

Metabolic acidosis and alkalosis and a respiratory acidosis were all ineffective in changing the rate of sodium transport from blood to brain during a 10 -min exposure. In contrast, other investigators have presented evidence that a metabolic acidosis of $1 \mathrm{~h}$ in duration reduced the sodium $P S$ product by $25 \%$ (Murphy and Johanson, 1989). The time of exposure to the altered blood $\mathrm{pH}$ is the main difference between these studies and probably accounts for the different results.

Recently the isoform of carbonic anhydrase desig-

TABLE 4. Effect of $p H, \mathrm{PCO}_{2}$, and inhibitors of sodium transport on $\mathrm{pCPV}$ and $\mathrm{pCBF}$

\begin{tabular}{lccccr}
\hline \multicolumn{1}{c}{ Condition } & $\mathrm{pH}$ & $\mathrm{PCO}_{2}$ & $\begin{array}{c}p C P V \\
(\mu \mathrm{l} / \mathrm{g})\end{array}$ & $\begin{array}{c}p C B F \\
(\mathrm{ml} / \mathrm{g} / \mathrm{min})\end{array}$ & $\mathrm{n}$ \\
\hline Low pH/normal $\mathrm{PCO}_{2}$ & $7.03 \pm 0.01^{a}$ & $45.6 \pm 2.4^{\prime \prime}$ & $3.88 \pm 0.19$ & $1.52 \pm 0.08^{\prime \prime}$ & 5 \\
Control & $7.34 \pm 0.01$ & $36.8 \pm 1.2$ & $3.64 \pm 0.18$ & $1.03 \pm 0.06$ & 11 \\
High pH/normal $\mathrm{PCO}_{2}$ & $7.76 \pm 0.01^{a}$ & $38.1 \pm 1.5$ & $2.58 \pm 0.22^{\prime}$ & $0.96 \pm 0.07$ & 7 \\
Normal pH/high $\mathrm{PCO}_{2}$ & $7.38 \pm 0.01$ & $84.4 \pm 2.3^{\prime \prime}$ & $2.67 \pm 0.35$ & $1.70 \pm 0.06^{\circ}$ & 3 \\
DMA $(25 \mu M)$ & $7.40 \pm 0.01$ & $34.0 \pm 1.6$ & $3.67 \pm 0.46$ & $1.08 \pm 0.07$ & 5 \\
Acetazolamide $(1 \mathrm{mM})$ & $7.40 \pm 0.03^{\circ}$ & $34.4 \pm 1.2$ & $2.92 \pm 0.51$ & $1.34 \pm 0.04^{\prime}$ & 4 \\
\hline
\end{tabular}

Data are mean $\pm \mathrm{SE}$ values

" $p \leq 0.001,{ }^{b} p \leq 0.01,{ }^{c} p \leq 0.05$ for comparison of control versus modified conditions. 


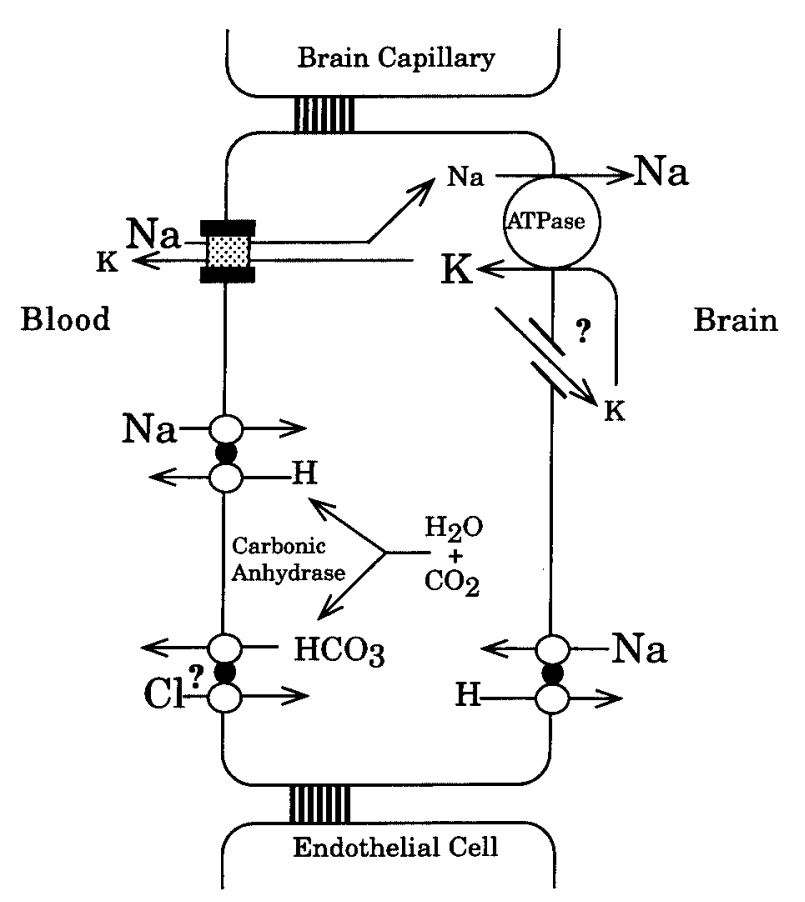

FIG. 5. Model of blood to brain sodium transport.

nated CA IV, which catalyzes the reaction of $\mathrm{CO}_{2}$ and $\mathrm{H}_{2} \mathrm{O}$ to form $\mathrm{H}^{+}$and $\mathrm{HCO}_{3}{ }^{-}$, has been identified on the luminal membrane of the brain capillary (Ghandour et al., 1992). The localization of this membrane-bound isoform of carbonic anhydrase on the luminal side of the BBB led us to hypothesize that inhibition by acetazolamide would reduce sodium transport. Our data with acetazolamide confirm the results of Murphy and Johanson (1989) that production of $\mathrm{H}^{+}$by carbonic anhydrase is not rate limiting for the $\mathrm{Na}^{+} / \mathrm{H}^{+}$exchange mechanism of the luminal membrane of the $\mathrm{BBB}$.

These transport systems, along with the $\mathrm{Na}^{+}, \mathrm{K}^{+}$ATPase located in the basolateral membrane of the $\mathrm{BBB}$, are thought to provide the driving force for net sodium and water secretion (Schielke and Betz, 1993). Figure 5 presents our current model for sodium transport at the $\mathrm{BBB}$. We have included a $\mathrm{Cl}^{--} / \mathrm{HCO}_{3}{ }^{-}$ exchanger in the luminal membrane that requires experimental verification. This transport system along with the DMA-sensitive $\mathrm{Na}^{+} / \mathrm{H}^{+}$exchanger would lead to neutral $\mathrm{NaCl}$ transport across the $\mathrm{BBB}$, as occurs in epithelia (Cremaschi et al., 1992). Our reasoning is that simultaneous $\mathrm{Na}^{+} / \mathrm{H}^{+}$and $\mathrm{Cl}^{-} / \mathrm{HCO}_{3}{ }^{-} \mathrm{ex}-$ change could provide for coupling between $\mathrm{Na}^{+}$and $\mathrm{Cl}$ transport as has been shown for epithelia (Cremaschi et al., 1992). In addition, other investigators have shown carrier-mediated chloride transport at the BBB that is not linked to $\mathrm{Na}^{+}$transport (Smith and Rapoport, 1984).

The model also includes an $\mathrm{Na}^{+} / \mathrm{H}^{+}$exchanger in the abluminal membrane. This transport system was identified from the effect of amiloride on isolated rat brain capillaries (Betz, 1983b). The $\mathrm{Na}^{+} / \mathrm{H}^{+}$exchangers are recognized as a gene family consisting of at least four isoforms, designated NHE 1-4. NHE $I$ is probably expressed in all mammalian cells, located in the basolateral membrane and functions in $\mathrm{pH}$ and volume regulation. In contrast, NHE 3 is thought to reside primarily in the apical membranes in epithelial cells and to function in neutral $\mathrm{NaCl}$ transport involving a $\mathrm{Cl}^{-} / \mathrm{HCO}_{3}{ }^{-}$exchanger (Levine et al., 1993; Tse et al., 1993 $a, b)$. It is an attractive hypothesis to suggest that the brain capillary endothelium may also have asymmetrical expression of the $\mathrm{Na}^{+} / \mathrm{H}^{+}$exchange isoforms based on similar functional considerations.

Our data suggest that the DMA-sensitive $\mathrm{Na}^{\prime} / \mathrm{H}^{\prime}$ exchanger and the PAM-sensitive sodium channel are located in the luminal membrane of the BBB. The low concentrations used, combined with the very short exposure time of $10 \mathrm{~min}$, would most likely not allow either DMA or PAM to penetrate into the brain extracellular space to a sufficiently high concentration to inhibit $\mathrm{Na}^{+}$transport at the abluminal membrane. Furthermore, these low concentrations should not inhibit other cellular process such as the $\mathrm{Na}^{\prime}, \mathrm{K}^{+}$-ATPase or oxidative metabolism (Frelin et al., 1988; Kleyman and Cragoe, 1988). The observation that DMA and PAM reduce blood to brain sodium transport suggests that the luminal membrane may be rate limiting for transendothelial transport of sodium. Confirmation of our speculation on the location of these transport systems in the luminal membrane of the BBB will require further experiments such as immunohistochemistry with specific antibodies to identify these proteins as has been done for CA IV (Ghandour et al., 1992) or the glucose transporter (Gerhart et al., 1989).

Improved knowledge of the mechanisms of ion transport may allow the use of specific drug therapy to reduce edema formation during the early phase of focal cerebral ischemia (Betz et al., 1989b). The first $6 \mathrm{~h}$ of cerebral ischemia is characterized by a net increase in content of brain cations that accounts for the net increase in brain water (Young et al., 1987; Betz et al., 1989a; Menzies et al., 1993). Furthermore, the rate of sodium transport appears to be selectively increased during this period of ischemia (Ennis et al., 1990; Schielke et al., 1991; Dickinson and Betz, 1992) through a stimulation of $\mathrm{Na}^{+}, \mathrm{K}^{+}$-ATPase (Schielke et al., 1991). The more specific amiloride analogues may permit targeting of these sodium transport systems to reduce edema formation during focal cerebral ischemia.

Acknowledgment: This work was supported by grant NS23870 from the National Institutes of Health. We wish to thank the staff of the Extracorporeal Circulation Laboratory of the Department of Surgery for their generous donation of sheep RBCs. We also want to thank Dr. R. F. Keep for many useful discussions and suggestions about this work. 


\section{REFERENCES}

Betz A. L. (1983a) Sodium transport from blood to brain: inhibition by furosemide and amiloride. I. Neurochem. 41, 1158-1164.

Bct\% A. L. ( 1983b) Sodium transport in capillaries isolated from rat brain. J. Neurochem. 41, 1150-1157.

Betr. A. L.. Ennis S. R., and Schielke G. P. (1989a) Blood-brain barrier sodium transport limits the development of brain edema during partial ischemia. Stroke 20, 1253-1259.

Bet A. L., Iannotti F., and Hoff J. T. (1989b) Brain edema: a classification based on blood-brain barrier integrity. Cerebrovasc. Brain Metab. Rev. 1, 133-154.

Bickler P. E., Litt L., Banville D. L., and Severinghaus J. W. ( 1988 ) Effect of acetazolamide on cerebral acid-base balance. J. Appl. Physiol. 65, 422-427.

Cremaschi D., Porta C., Botta G., and Meyer G. (1992) Nature of the neutral $\mathrm{Na}^{+}-\mathrm{Cl}$-coupled entry at the apical membrane of rabbit gallbladder epithelium: IV. $\mathrm{Na}^{+} / \mathrm{H}^{+}, \mathrm{Cl} / \mathrm{HCO}_{3}{ }^{-}$double exchange, hydrochlorothiazide-sensitive $\mathrm{Na}^{+}-\mathrm{Cl}^{-}$symport and $\mathrm{Na}^{+}-\mathrm{K}^{+}-2 \mathrm{Cl}^{-}$cotransport are all involved. J. Membr. Biol. 129, $221-235$.

(rone C. (1984) Lack of selectivity to small ions in paracellular pathways in cerebral and muscle capillaries of the frog. J. Physiol. (Lond.) 353, 317-337.

Dickinson L. D. and Betz A. L. ( 1992) Attenuated development of ischemic brain edema in vasopressin-deficient rats. J. Cereb. Blood Flow Metab. 12, 681-690.

Innis S. R., Keep R. F., Schielke G. P., and Betz A. L. (1990) Decrease in perfusion of cerebral capillaries during incomplete ischemia and reperfusion. J. Cereb. Blood Flow Metab. 10, $213-220$

linnis S. R., Ren X. D., and Betz A. L. (1993) Mechanisms of blood to brain sodium transport studied with in situ perfusion. (Abstr.) J. Cereb. Blood Flow Metab. 13 (Suppl.), S84.

Ennis S. R., Ren X. D., and Betz A. L. (1994) Transport of $\alpha$ aminoisobutyric acid across the blood-brain barrier studied with in situ perfusion of rat brain. Brain Res. 643, 100-107.

Ermisch A.. Rühle H. J., Kretzschmar R., and Baethmann A. (1991) On the blood-brain barrier to peptides: specific binding of atrial natriuretic peptide in vivo and in vitro. Brain Res. 554, 209 216

Fenstermacher J., Blasberg R., and Patlak C. (1981) Methods for quantifying the transport of drugs across the brain barrier systems. Pharmacol. Ther. 14, 217-248.

Frelin C., Barbry P., Vigne P., Chassande O., Cragoe E. J., and Lazdunski M. (1988) Amiloride and its analogs as tools to inhibit $\mathrm{Na}$ transport via the $\mathrm{Na}$ channel, the $\mathrm{Na} / \mathrm{H}$ antiport and the $\mathrm{Na} / \mathrm{Ca}$ exchanger. Biochimie 70, 1285-1290.

(ierhart D. Z., LeVasseur R. J., Broderius M. A., and Drewes L. R. (1989) Glucose transporter localization in brain using light and electron immunocytochemistry. J. Neurosci. Re's. 22, 464-473.

Ghandour M. S., Langley O. K., Zhu X. L., Waheed A., and Sly W. S. (1992) Carbonic anhydrase IV on brain capillary endothelial cells: a marker associated with the blood-brain barrier Proc. Natl. Acad. Sci. USA 89, 6823-6827.

Iharagi M., Niwa M., and Ozaki M. ( 1989 ) Atrial natriuretic peptide modulates amiloride-sensitive $\mathrm{Na}^{+}$transport across the bloodbrain barrier. J. Neurochem. 53, $1802-1806$
Kleyman T. R. and Cragoe E. J. (1988) Amiloride and its analogs as tools in the study of ion transport. J. Membr. Biol. 105, 1 21.

Levine S. A., Montrose M. H., Tse C. M., and Donowitz M. (1993) Kinetics and regulation of three cloned mammalian $\mathrm{Na}{ }^{+} / \mathrm{H}^{+}$ exchangers stably expressed in a fibroblast cell line. J. Biol Chem. 268, 25527-25535.

Light D. B., Corbin J. D., and Stanton B. A. (1990) Dual ionchannel regulation by cyclic GMP and cyclic GMP-dependent protein kinase. Nature 344, 336-339.

Menzies S. A., Betz A. L., and Hoff J. T. (1993) Contributions of ions and albumin to the formation and resolution of ischemic brain edema. J. Neurosurg. 78, 257-266.

Murphy V. A. and Johanson C. E. (1989) Acidosis, acetazolamide, and amiloride: effects on ${ }^{22} \mathrm{Na}$ transfer across the blood-brain and blood-CSF barriers. J. Neurochem. 52, 1058-1063.

Pardridge W. M. (1983) Brain metabolism: a perspective from the blood-brain barrier. Physiol. Rev. 63, 1481-1535.

Patlak C. S., Blasberg R. G., and Fenstermacher J. D. (1983) Graphical evaluation of blood to brain transfer constants from multipletime uptake data. J. Cereb. Blood Flow Metab. 3, 1-7.

Sakurada O., Kennedy C., Jehle J., Brown J. D., Carbin G. L., and Sokoloff L. (1978) Measurement of local cerebral blood flow with iodo $\left({ }^{14} \mathrm{C}\right)$ antipyrine. Am. J. Physiol. 234, H59-H66.

Schielke G. P. and Betz A. L. (1993) Electrolyte transport, in Physiology and Pharmacology of the Blood-Brain Barrier (Bradbury M. W. B., ed), pp. 221-244. Springer-Verlag, Heidelberg.

Schielke G. P., Moises H. C., and Betz A. L. (1991) Blood to brain sodium transport and interstitial fluid potassium concentration during early focal ischemia in the rat. J. Cereb. Blood Flow Metab. 11, 466-471.

Siesjö B. K. and Ingvar M. (1983) Blood flow, in Handbook of Neurochemistry (Lajtha A., ed), pp. 653-688. Plenum Press, New York.

Smith Q. R. and Rapoport S. I. (1984) Carrier-mediated transport of chloride across the blood-brain barrier. J. Neurochem. 42, $754-763$.

Steardo L. and Nathanson J. A. (1987) Brain barrier tissues; end organs for atriopeptins. Science $\mathbf{2 3 5}, \mathbf{4 7 0 - 4 7 3}$.

Takasato Y., Rapoport S. I., and Smith Q. R. (1984) An in situ brain perfusion technique to study cerebrovascular transport in the rat. Am. J. Physiol. 247, H484-H493.

Tse C.-M., Levine S. A., Yun C. H. C., Brant S. R., Pouyssegur J., Montrose M. H., and Donowitz M. ( 1993a) Functional characteristics of a cloned epithelial $\mathrm{Na}^{+} / \mathrm{H}^{+}$exchanger (NHE3): resistance to amiloride and inhibition by protein kinase C. Proc. Natl. Acad. Sci. USA 90, 9110-9114. ,

Tse M., Levine S., Yun C., Brant S., Counillon L. T., Pouyssegur J., and Donowitz M. ( $1993 b$ ) Structure/function studies of the epithelial isoforms of the mammalian $\mathrm{Na}^{+} / \mathrm{H}^{+}$exchanger gene family. J. Membr. Biol. 135, 93-108.

Vigne P., Champigny G., Marsault R., Barbry P., Frelin C., and Lazdunski M. (1989) A new type of amiloride-sensitive cationic channel in endothelial cells of brain microvessels. J. Biol. Chem. 264, 7663-7668.

Young W., Rappaport Z. H., Chalif D. J., and Flamm E. S. ( 1987 ) Regional brain sodium, potassium, and water changes in the rat middle cerebral artery occlusion model of ischemia. Stroke 18, $751-759$ 